\title{
Effects of Impulse Voltages on Transformer Windings
}

$\mathrm{I}^{\mathrm{N}}$ a paper by Dr. T. E. Allibone, D. B. Mackenzie and F. R. Perry (J. Inst. Elec. Eng., 80, 118; 1937), the results obtained in a very thorough research on the effects of impulse voltages are given.

To understand what is meant by 'impulse voltage' we have to consider the experiments that have been made during the past seventy years. In 1860 Lord Kelvin wrote a paper describing researches that had been made in his laboratory on the voltage required to produce a spark between spherical electrodes. $\mathrm{He}$ used primary batteries in series, and obtained some evidence that the spark occurred when the maximum stress between the electrodes attained a definite value depending on the barometric pressure. If higher voltages had been obtainable, he would have found that except when the electrodes were close together and when they were so far apart that brush discharges appeared on them, there was a certain stress at which the discharge occurred. This is definitely proved by the results obtained by several experimenters some fifty years ago. Knowing, therefore, how to compute the sparking voltages between the electrodes in air in certain cases, attempts were made by electrical engineers to determine experimentally the electric stresses that would produce sparking voltages in materials like glass, ebonite, porcelain and even in non-homogeneous substances like the insulating wrappings of cables. Owing to the very high voltages required, alternating current pressures obtained from a transformer were used. This made a very large high-tension laboratory necessary and greatly increased the cost of research at high pressures.

Instead of using a very high pressure transformer, experimenters sometimes employed batteries of condensers. If there were ten such batteries and they were charged to a potential $V$ in parallel, then in series they would give a potential difference of $10 \mathrm{~V}$. But as Kelvin had shown in 1853, this discharge might be oscillatory, obtaining a maximum voltage which is generally taken to measure the maximum stress and then trailing off in a series of smaller oscillations. The effect of the rush of this oscillating quantity of electricity is sometimes deleterious to the transformer windings. As Duddell pointed out many years ago, when a transformer broke down after a rush of electricity through it, the place of breakdown was generally in the windings first subjected to the effects of the rush. Apart from testing, this problem is of vital importance in power transmission lines where we often have inductance and capacity in series, and a neighbouring lightning stroke or a short circuit may start a travelling 'impulse voltage'.

Messrs. Allibone, Mackenzie and Perry have analysed the effects of the applications of impulse voltages of varied wave shapes to transformers. They have considered both single and multiple 'transients'. They have also experimented on model transformers of different winding characteristics and on both single-phase and three-phase transformers. The constants of these transformers must be known as they determine the voltage distribution within the wind. ings due to the impact of a surge. They have been calculated and measured, and the effect of altering them has been examined. The agreement obtained between theory and experiment is good. The trans. ference of surges from one winding to another is considered. They also discuss the testing of transformers with impulse voltages.

In Germany and Switzerland, surge voltages have been used for transformer testing for several years, and this has improved the quality of the transformers. Recently, test schedules have been suggested both in the United States and in Great Britain with the same object in view. The authors conclude that a knowledge of the behaviour of transients in transformer windings is essential if the most efficient use is to be made of the insulation employed. The problem is made more complex owing to the wide diversity of connexions possible between the windings and by the influence which externally connected circuits may have on the transient within the winding. At the same time, as the designer makes research on the impulse voltages within the windings, he must ascertain the behaviour of the insulation employed under a variety of applied impulses, so that by combining the knowledge of voltage distribution with a knowledge of the electric strength of materials, a forecast of the breakdown voltage of the transformer under test conditions can be obtained.

\section{Alloys of Magnesium}

$\mathrm{M}$ AGNESIUM, the sixth most abundant element in the world, was first made commercially in 1857, and in the last twenty years its price has dropped from 25s. to $1 s$. $3 d$. a pound. The recent demand for lightness in construction has led to a great deal of research being undertaken in many countries on the possibility of using magnesium alloys in place of the heavier aluminium alloys as engineering materials, and the results obtained are scattered in many scientific and technical journals. The Metallurgy Research Board of the Department of Scientific and Industrial Research arranged for the results to be summarized by Dr. J. L. Haughton and W. E. Prytherch*.

One of the great limitations to the use of mag. nesium alloys at the present time is that they tend to corrode very readily in certain types of water, although the corrosion is not always so severe as was originally believed. Much work has been done to find some metal which would notably reduce this trouble, and $0.5-2 \cdot 5$ per cent manganese has an

* Department of Scientiflc and Industrial Research. "Magnesium and its Alloys". By Dr. J. L. Haughton and W. E. Prytherch. Pp. viii $+100+5$ plates. (London: H.M. Stationery Óffice, 1937.) $28.6 d$. net. 
appreciable influence in this direction. Failing further progress in this field, magnesium alloys will probably have to be protected against severe corrosive conditions by paints applied over some chemically produced film, without which paints will not adhere satisfactorily. Special reference is made to the selenium and to the chromate treatment for the production of protective films as a basis for painting, and it is pointed out that the choice of paint to put on the films is important, as many pigments suitable for iron and steel actually stimulate corrosion on magnesium alloys. Reference is also made to the corrosive action of 'leaded' motor and aviation fuels on magnesium cylinders. It is stated that work at the Chemical Research Laboratory has shown that the addition of 1 per cent of quinoline to the fuel inhibits this action and exerts no harmful effect in its anti-knock properties.

Owing to the ease with which molten magnesium and its alloys combine with oxygen, special methods have to be employed for melting and casting. With the methods described in the monograph, however, it is stated that there is no difficulty in producing castings in magnesium alloys either in sand or permanent moulds.

The monograph summarizes the mechanical properties at room temperatures of the magnesium alloys at present used in industry. These are almost entirely confined to alloys with aluminium and zinc, of ten containing a small amount of manganese introduced to improve the corrosion-resisting properties. With alloys containing 8 per cent or more of aluminium, it is usually possible to produce increased hardness and a general improvement in properties by suitable heat treatment. This takes the form of exposure to a temperature of $420^{\circ} \mathrm{C}$. for a few hours, sometimes followed by tempering for 4-7 days at about $150^{\circ} \mathrm{C}$. Increased ductility can be produced by adding cadmium, and reference is made to an alloy consisting of aluminium, silver, manganese and calcium, which has been found suitable for use in stressed parts at room temperature.

A number of possible uses of magnesium alloys involve the exposure of the metal to elevated tem. peratures, and for this reason their mechanical properties when hot become important. The results of tests up to $300^{\circ} \mathrm{C}$. are given for various alloys. Silver, it has been found, increases the ultimate strength of magnesium up to $290^{\circ} \mathrm{C}$. but its effect when used alone is not so marked as that of aluminium. Recently cerium has been added, which is stated to have a pronounced effect in increasing the strength of magnesium at elevated temperatures. Even small quantities, of the order of 1 per cent, have a remarkable effect in increasing the hardness at $300^{\circ} \mathrm{C}$. The addition of a small amount of calcium to the cerium-magnesium alloys is beneficial in preventing oxidation during melting and heat treatment as well as in improving the age-hardening properties. The increased hardness due to heat treatment is, however, relatively small, even when calcium is present.

A harder alloy can be produced by adding nickel to the cerium-magnesium alloys, but such alloys were found to be very liable to corrosion. This can be reduced slightly by replacing nickel by cobalt and manganese.

The final chapter of the monograph contains reproductions of all known constitution-temperature diagrams for the alloys of magnesium in the form considered by the authors to be most nearly correct. F. C. T.

\section{Conditions in the Special Areas of Great Britain}

$\mathrm{S}^{\mathrm{ni}}$ IR GEORGE GILLETT'S admirable first report as Commissioner for the Special Areas of England and Wales, covering the year ended Septem. ber 30, 1937, shows no departure from the example of frankness and independence of judgment that was set by Sir Malcolm Stewart. The report is indeed in striking contrast to the evidence tendered by the Board of Trade to the Royal Commission on the Geographical Distribution of the Industrial Popula. tion. Like Sir Malcolm Stewart, Sir George Gillett stoutly upholds the principle that the State should control the location of industry, asserting that the introduction of tariffs and quotas has enhanced the Government's responsibility in this matter, and that social and strategic as well as economic causes are driving the Government to abandon the old laissezfaire attitude. The recommendations in the recent report of the Import Duties Advisory Committee on the present position and future development of the iron and steel industry, no less than the appointment of the Royal Commission, illustrate this tendency.

The first recommendation is that the conclusions of the British Iron and Steel Federation in regard to all schemes of development of the industry should, whether favourable or not, be reported to an independent body looking to the general public interest.
This independent body is to be the Import Duties Advisory Committee itself, and Sir George Gillett points out that this recognition that matters which concern the welfare of thousands of our fellow citizens are properly to be considered in relation to their social and broad economic consequences, as well as in relation to the profit and loss account of the individual concern, marks a great advance.

The second recommendation to which Sir George directs attention relates to the need for dealing with the problem of restoration on a systematic and comprehensive scale to avoid the serious risk of creating extensive areas of broken and barren land by quarrying ironstone over large new areas. Sir George Gillett considers that this touches on one of the vital problems of the Special Areas, and that the recommendations should be extended to apply to all industries, such as the coal, chemical and brick industries, which are apt to leave scars on the landscape, and he suggests that the tragic relics of the past should be avoided by a system of compulsory insurance or by putting responsibility for clearance on the industry as a whole.

As Sir George Gillett points out, the ideal solution is for new industries to be established on sites which have already been scarred and spoilt for any but industrial purposes, as in the huge new steel works 